\title{
Gastric cancer in a south Wales valley
}

\author{
L K ATUHAIRE, ${ }^{1}$ M J CAMPBELL, ${ }^{1}$ A L COCHRANE, ${ }^{2}$ M JONES, ${ }^{2}$ \\ AND F MOORE
}

From the Department of Community Medicine and Medical Statistics, ${ }^{1}$ Southampton, and the MRC Epidemiology Unit, ${ }^{2}$ Cardiff, UK

The most recent paper about gastric cancer in south Wales is that by Craven et al who covered the extensive publications on the subject, noting, for example, the pronounced social class relation and the high SMRs in certain occupational groups such as miners. ${ }^{1}$ They also discuss the paper by Stukonis and Doll, which suggests that hard work and a healthy appetite are more probable aetiological factors than specific occupational risks. ${ }^{2}$ The results of Craven $e t$ al, however, based mainly on cancer registration rates show miners with by far the highest registration rates for gastric cancer when compared with other occupations. There was, therefore, every reason to explore the hypothesis that exposure to coal dust might play a part in the aetiology of gastric cancer in Wales.

The 30 year follow up of the men in the Rhondda Fach, consisting of non-miners and miners of whom $99.9 \%$ were carefully followed up for 30 years, provided an excellent data base for testing the hypothesis. $^{3}$

Expected deaths for gastric cancer were calculated using the death rates for England and Wales for the same period. Statistical significance of the differences

Accepted 5 August 1985 in SMRs between groups was calculated using Poisson regression ${ }^{45}$ with the statistical package GLIM. $^{6}$

\section{Results and comment}

Table 1 shows the SMRs for gastric cancer for the 30 year follow up of 7939 men by occupation and category of pneumoconiosis. Although some of the results of individual categories of pneumoconiosis are somewhat bizarre, the comparison between miners and ex-miners combined and non-miners is not significant $\left(\chi_{2}^{2}=0.31, p=0.86\right)$. Within miners and ex-miners a test for heterogeneity also failed to come close to significance $\left(\chi_{6}^{2}=3.44, \mathrm{p}=0.75\right)$.

At this stage we must point out one possible source of bias. Miners and ex-miners, particularly those with pensions for pneumoconiosis, are, at death, much more likely to have postmortem examinations. This might increase the diagnosis of gastric cancer among miners and ex-miners, whereas among non-miners the death certificates might have an excess of carcinomatosis only being diagnosed. We have examined this by looking at "site unspecified" (ICD 199). The SMR, on our data, is 94 for non-miners and, somewhat surprisingly, 125 for miners and

Table 1 Observed deaths and SMRs for gastric cancer (ICD code 151,6th, 7th, 8th, and 9th revisions for men aged $20-74$ at survey by occupation and category of pneumoconiosis)

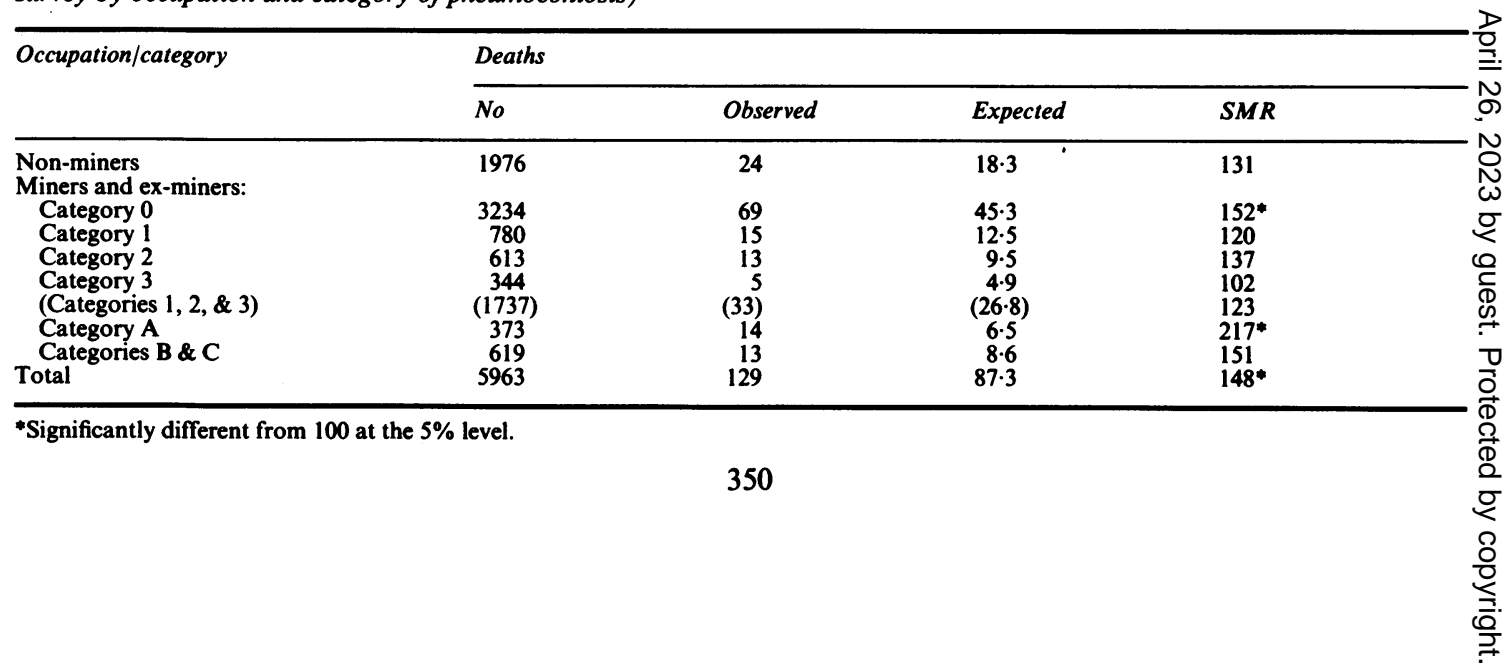


Table 2 Mortality rates by age from gastric cancer in 30 years for miners and ex-miners, and non-miners (all ages)

\begin{tabular}{|c|c|c|c|c|c|c|}
\hline \multirow[t]{2}{*}{ Age groups } & \multicolumn{3}{|c|}{ Miners and ex-miners } & \multicolumn{3}{|c|}{ Non-miners } \\
\hline & No & Dead & $\%$ & No & Dead & $\%$ \\
\hline $\begin{array}{l}20-24 \\
25-44 \\
45-64 \\
65-74 \\
\geqslant 75\end{array}$ & $\begin{array}{r}323 \\
2470 \\
2463 \\
707 \\
219\end{array}$ & $\left.\begin{array}{r}1 \\
25 \\
86 \\
17 \\
6\end{array}\right\}$ & $\begin{array}{l}0.3 \\
1.0 \\
3.5 \\
2.5\end{array}$ & $\begin{array}{r}479 \\
1117 \\
329 \\
51 \\
24\end{array}$ & $\left.\begin{array}{c}2 \\
11 \\
10 \\
1 \\
-\end{array}\right\}$ & $\begin{array}{l}0.4 \\
1.0 \\
3.0 \\
1.3\end{array}$ \\
\hline All & 6182 & 135 & $2 \cdot 2$ & 2000 & 24 & 1.2 \\
\hline
\end{tabular}

Comparison of miners and ex-miners with non-miners, $\chi^{2}{ }_{1}=0.39, p=0.54$.

Table 3 Case-control study for deaths from gastric cancer in ex-miners in three towns

\begin{tabular}{lllllll}
\hline Status No & \multicolumn{2}{l}{ Years on coal face } & \multicolumn{3}{l}{ Years underground } \\
\cline { 2 - 7 } & Mean & $S D$ & p Value & Mean & $S D$ & $p$ Value \\
\hline Cases (37) & 14.7 & 12.1 & $>0.5$ & 22.1 & 13.6 & $>0.5$ \\
Controls (148) & 14.5 & 12.9 & & 21.3 & 13.4 & \\
\hline
\end{tabular}

Cases: all ex-miners dying from gastric cancer.

Controls: randomly selected ex-miners born in same year as cases.

ex-miners which is, however, not statistically significant $\left(\chi_{1}^{2}=0.2, p=0.65\right)$ because of the low number of deaths in the two groups ( 3 for non-miners, and 15 for miners and ex-miners).

A possibly more stringent test of the hypothesis is to examine trends by category of simple pneumoconiosis, as these categories are closely related to dust dosage. There is a minor difficulty as to how to group the categories, as the attack and progression rate of progressive massive fibrosis is independent of further exposure to dust. We have analysed two different groupings, $0,1,2,3, \mathrm{~A}, \mathrm{BC}$, and $0,1,2,3 \mathrm{ABC}$. The results of the first give the results $\chi_{1}^{2}=0 \cdot 13, \mathrm{p}=0.72$ and the second $\chi_{1}^{2}=0.12$, $\mathbf{p}=\mathbf{0 . 7 3}$. There is thus no evidence of a trend.

Table 2 shows the gastric cancer mortality by age in non-miners, and miners and ex-miners. Here there is no evidence of any significant difference (allowing for age $\chi_{1}^{2}=0.39, p=0.54$ ). It must be admitted, however, that the non-miner group aged 75 and over is small.

We thought that we could pursue the argument further by using our industrial histories, taken in three towns in the Rhondda Fach in 1950 and 1953, of all the miners and ex-miners. We had available indices for "years on the coalface" and "years underground." We also hoped that any differences shown by the results using the two indices might give us an idea as to whether there were any other underground factors that might be important. Unfortunately we could use only the detailed histories of those designated ex-miners in 1950 and 1953, as the others, the miners of that time had further exposure to dust. There were 37 ex-miners, so designated, who died of gastric cancer in the next 30 years. Four controls and one reserve were chosen from all the ex-miners born in the same years as the cases who did not die from gastric cancer. Table 3 shows the results for years on the coalface and years underground. The results for years on the coalface provide further evidence against the coal dust hypothesis, and the results for years underground give little scope for other underground factors. We must admit, however, that the number of cases of gastric cancer among the ex-miners is small.

\section{Discussion}

Using an excellent data base we have tested the hypothesis that exposure to coal dust increases the risk of gastric cancer, using standard analytical methods, and been unable to find support for it. We are conscious that our results apply only to one small area in Wales and that other factors may be important elsewhere-the type of coal, for example. We are nevertheless surprised that our results differ so sharply from those of others. We know from our own experience that relying on death and registration certificates for information about occupation may introduce error but we would not expect it to introduce bias. Our data really only differ from those of others by the inclusion of ex-miners who have 
taken up other occupations, but the SMR of ex-miners is $141(95 \%$ confidence limits $110 \cdot 2-178 \cdot 0)$ and is not significantly different from that of the miners at $157 \cdot 5$ (95\% confidence limits $119 \cdot 6-203 \cdot 6)$. So the problem remains.

\section{References}

${ }^{1}$ Craven JL, Baum M, West RR. Variations in gastric cancer incidence in South Wales. Clin Oncol 1979;5:341-51.
${ }^{2}$ Stukonis M, Doll R. Gastric cancer in man and physical activity a work. Int J Cancer 1969;4:248-54.

${ }^{3}$ Atuhaire LK, Campbell MJ Cochrane AL, Jones M, Moore F Mortality of men in the Rhondda Fach 1950-80. Br J Ind Med 1985;42:741-5.

${ }^{4}$ Breslow NE, Lubin JD, Marek P, Langholz B. Multiplicative models and cohort analysis. Journal of the American Statistical $\frac{}{\sigma}$ Association 1983;78:1-12.

${ }^{5}$ Berry G. The analysis of mortality by the subject-years method. Biometrics 1983;39:173-84.

${ }^{6}$ Baker RJ, Nelder JA. The GLIM system: release 3. Oxford: National Algorithm Group, 1978. 